\section{Photocatalytic Sonogashira Coupling on Polymeric Pyrazine-CuO Nanoparticles}

\section{Gategory}

Polymer-Supported

Synthesis

\section{Key words}

pyrazines

copper oxide

supramolecular

assembly

nanoparticles

photocatalysis

SonogashiraHagihara crosscoupling
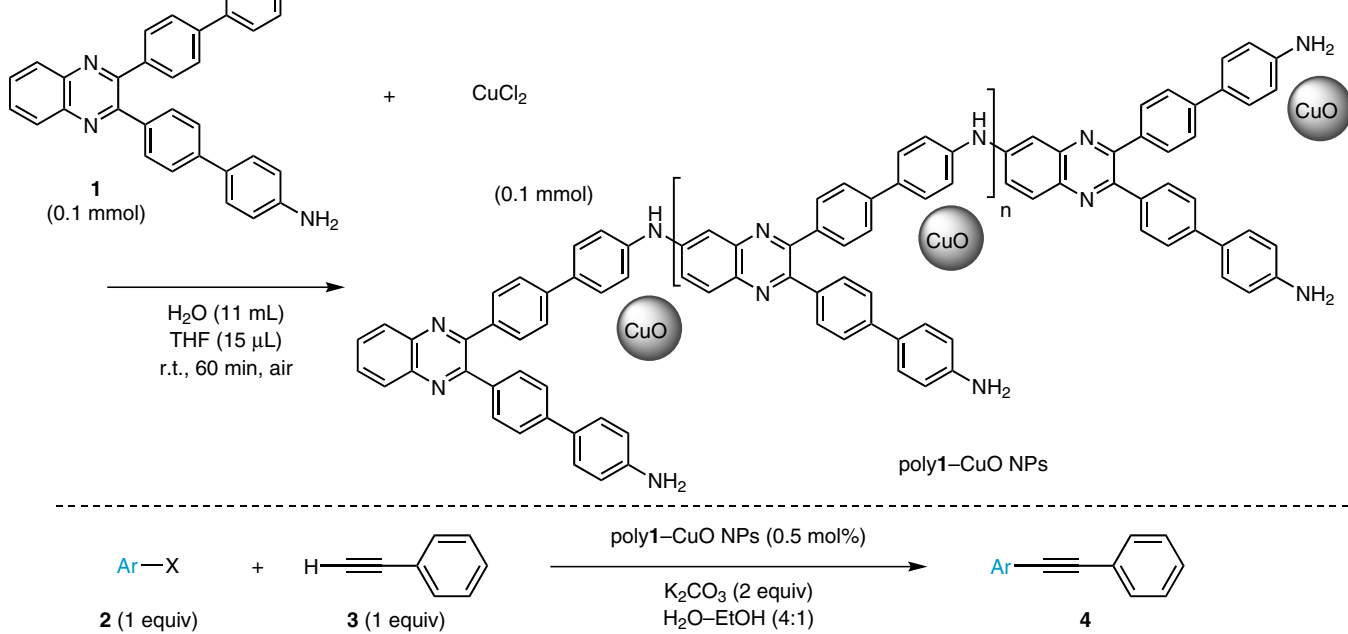

$$
\mathrm{X}=\mathrm{Cl}, \mathrm{Br} \text { or }
$$

3 (1 equiv)

Selected results:

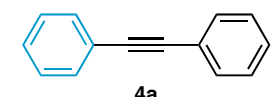

$\mathrm{X}=\mathrm{Cl}, 4 \mathrm{~h}, 60 \%$ yield

$\mathrm{X}=\mathrm{Br}, 3 \mathrm{~h}, 80 \%$ yield

$X=I, 3 h, 89 \%$ yield
in dark, $X=I, 12 \mathrm{~h}, 30 \%$ yield

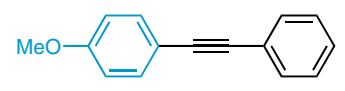

$\mathrm{X}=\mathrm{I}, 4 \mathrm{~h}, 75 \%$ yield

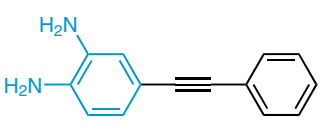

$4 f$

$\mathrm{X}=\mathrm{Br}, 5 \mathrm{~h}, 75 \%$ yield

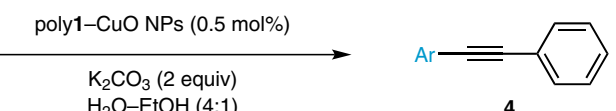

$\mathrm{H}_{2} \mathrm{O}-\mathrm{EtOH}(4: 1)$ r.t., $3-12 \mathrm{~h}$

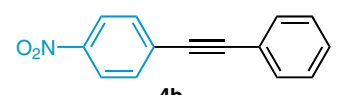

$4 \mathrm{~b}$

$\mathrm{X}=\mathrm{I}, 12 \mathrm{~h}, 45 \%$ yield

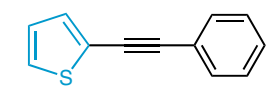

$4 \mathrm{e}$

$\mathrm{X}=\mathrm{Br}, 7 \mathrm{~h}, 78 \%$ yield

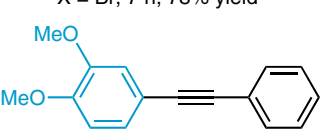

$\mathbf{4 g}$

$\mathrm{X}=\mathrm{Br}, 5 \mathrm{~h}, 72 \%$ yield

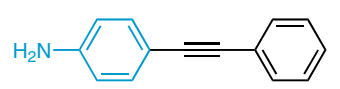

$\mathrm{X}=\mathrm{I}, 5 \mathrm{~h}, 78 \%$ yield

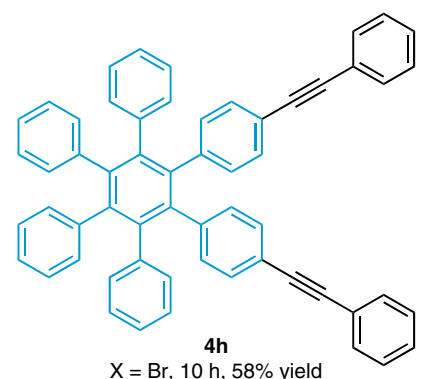

Significance: $\mathrm{CuO}$ nanoparticles stabilized on a polymeric amine (poly1-CuO NPs) were prepared by treatment of $\mathrm{CuCl}_{2}$ with the benzopyrazine-derived amine $\mathbf{1}$ in water under air. Poly1-CuO NPs promoted the photocatalytic Sonogashira coupling of aryl halides 2 with ethynylbenzene (3) under visible-light irradiation to give the corresponding products 4 in $\leq 89 \%$ yield.
Comment: Poly1-CuO NPs were characterized by means of FT-IR and UV-vis, and fluorescence spectroscopy and XRD, SEM, and TEM analyses. The reaction of iodobenzene with $\mathbf{3}$ in darkness gave 4a in 30\% yield. In the absence of poly1, $\mathrm{CuO}$ nanoparticles catalyzed the reaction to give 4a in 48\% yield in 12 hours. Poly1-CuO NPs were reused five times without significant loss of their catalytic activity.

sYNFACTS Contributors: Yasuhiro Uozumi, Yoichi M. A. Yamada, Aya Ohno

Synfacts 2016, 12(09), 0977 Published online: 18.08.2016

Dol: 10.1055/s-0035-1562749; Reg-No.: Y10816SF 